\section{NECESSIDADE E EFICÁCIA DA INFORMATIZAÇÃO EM HOTÉIS E EMPREENDIMENTOS EM GERAL}

Ney dos Santos

RESUMO: Informatizar é a palavra-chave para uma empresa estar atualizada tecnologicamente. Na hotelaria, como em qualquer atividade, deve se subordinar as necessidades do negócio às do cliente. A qualidade do resultado dependerá do uso das informações processadas o da adequação dos recursos humanos e materiais envolvidos. com im pacto direto no grau de satisfação do cliente. Informatizar é preciso e útil, e, bem feito, produz lucros e sucesso no negócio.

UNITERMOS: Hotelaria: informatização: banco de dados. Informatização na hotelaria: necessidade; eficácia; aplicação.

ABSTRACT: Information system is the keyword to achieve the state-of-the-art in any organization. In Hotels as of any other activities, the information system must to support the business needs and custome satisfaction. The business results will be dependent of the use of processing date, and the adequation of human and material resources, which will directly impact the level of customer satisfaction. The organizations want information systems and when they are well dereloped the results are more profits and business success.

KEY-WORDS: Hotel business: informatization; data base. Hotcl informatization: necessity; efectiveness; application.

\section{INTRODUÇÃo}

Informatizar é a palavra de ordem no momento. Em todos os segmentos de atividade esta ferramenta fantástica pode ajudar no sucesso do empreendimento. Como ferramenta que é, deve ser aplicada no lugar e na forma correta, e orientada com base nos princípios mo-

(*) Bacharel em Administração de Empresas. Gerente de Auditoria de Sistemas da Xerox do Brasil S.A. Especialista em Informática.

End. para corresp.: Av. Rodrigues Alves. 261 - CEP 20220 - Rio de Janeiro - RJ Brasil. dernos de administração. É um meio e não um fim. Colaborando na decisão de implementar ou modificar um sistema de informação computadorizado, este artigo destaca os pontos importantes a considerar na condução do processo, tanto em aspectos gerais quanto a detalhes particulares da atividade hoteleira.

\section{INFORMATIZAÇÃO EM HOTÉIS E EMPREENDIMENTOS EM GERAL}

A informática, atualmente, já faz parte da vida de todos nós. Na área de hotelaria isto também é um fato. Sem informação e capacidade de processá-la eficazmente, uma empresa não consegue mais prestar serviços no nível exigido pelos clientes, ficando inferiorizada para enfrentar concorrentes que se valem dos recursos tecnológicos de processamento da informação.

E aqui é importante esclarecer o que é informatizar uma empresa ou uma atividade. Informatizar não é simplesmente transferir as tarefas que são executadas manualmente para um computador, mantendo a forma e a maneira como são executadas. Informatizar é dotar a empresa de dados que contribuam para a eficácia no gerenciamento do negócio e que deve incluir, necessariamente, o atendimento às expectativas e requerimentos dos clientes aos quais pretende atender.

Antes de pensar em informatizar as atividades de um hotel, assim como de qualquer tipo de empresa ou atividade, deve-se definir que informações (dados) são necessárias, para quê servem e o quê se quer fazer com elas, para que possam ajudar efetivamente a conduzir negócio ao objetivo traçado.

Quando um empresário decide por construir ou adquirir um hotel, ele considera fatores como localização, demanda, categoria do serviço, existência de recursos humanos etc., como parte dos elementos que vão ajudar na tomada de decisão de fazer ou não o negócio. Estas informações são obtidas em diversas fontes privadas e governamentais, e geralmente estão armazenadas em ambientes computadorizados.

E aqui está a diferença. Os dados existem, porém se não estiverem dispostos de maneira a permitir uma análise adequada, não ajudam em nada a decisão. O problema portanto não é acumular dados e sim acumular os dados corretos e armazená-los de maneira a permitir seu manuseio racional.

Os dados servem para apoiar todas as etapas de operação, aumentando a produtividade e fornecendo resultados que permitem tomadas de decisão mais seguras, porém isto só vai ocorrer se estiverem organizados com estes objetivos, se forem confiáveis e estiverem disponivei no momento desejado. 
Um detalhe importante, muitas vezes ignorado, é que nenhum sis. tema de computação decide nada por nós. Os sistemas precisam ser programados para cumprir com sua finalidade, e a automação dos processos estará sempre diretamente relacionada à capacidade dos planejadores em dotar o sistema de recursos (de "hardware" e "software") para que execute o desejado.

Planejar e avaliar criteriosamente antes de partir para qualquer solução de informatização é a melhor maneira de assegurar o caminho mais adequado à situação desejada e que atenda aos requisitos de custo/benefício do instrumento e de satisfação do cliente.

Tratamento especial deve ser dado aos recursos humanos que vão operar o sistema. A falta de capacitação e compreensão do processo pelo pessoal que o opera é fatal para os resultados e tem impacto fortemente negativo no relacionamento com o cliente. Uma máxima em sistemas diz que as pessoas podem destruir um bom sistema e fazer funcionar bem um mal sistema. Ignorá-las e imaginar que se pode fazer um sistema imune a elas ou sem o apoio delas é fatal.

É muito comum a idéia de que a simples instalação de sistemas computadorizados vai resolver todos os problemas, reduzir pessoal, cortar custos e tornar tudo fácil. Isto algumas vezes é verdade, sob a ótica somente para dentro da empresa. Seria o mesmo que dizer que a simples troca do cavalo pelo carro resolveu todos os problemas de transporte na época. É verdade que não se precisou mais da cocheira, do tratador, da comida, do veterinário, dos arreios etc. Mas, em contrapartida, passou-se a precisar la garagem, do mecânico, do lavador, do combustível, dos pneus, da estrada. Embora seja uma comparação simplista, serve para mostrar que deve-se analisar os custos/benefícios de uma mudança, e a análise deve incluir até mesmo progresso, futurismo e benefícios para a sociedade, porque atrás disto certamente virá a lucratividade do negócio.

Ressata-se, ainda, que o hotel é a casa do cliente durante sua permanência no local. O hóspede vive dentro do hotel boa parte de seu tempo, e espera que a organização esteja preparada para atendê-lo. Sistemas ou pessoas que atrapalhem a solução das solicitações dos clientes depreciam uma organização.

Um hotel, uma vez instalado, tem em estoque para oferecer aos clientes, como produto primário, suas instalações. Quartos e salões são o estoque básico de um hotel. Todos os demais elementos são complementares e vão determinar a qualidade e nível de serviço oferecido.

É indispensável saber com segurança as condições de suas insta* lações, estoque disponível de quartos, configuração dos quartos, de- manda diária prevista (confirmada e por confirmar), quantidade de hóspedes por unidade, perfil dos hóspedes esperados, que hóspedes usam os serviços, a expectativa de ingresso de recursos financeiros e $c$ desencaixes "cash flow", entre diversas outras coisas

Dados desta natureza permitem definir uma série de necessidad operacionais como: quantidade de empregados em cada setor, cons mo de alimentos e bebidas pelo bar e restaurante, quando e como $r$ por estoques, disponibilidade de recursos financeiros etc. Um sistem que integre informações que permitam saber como estão se compo tando os vários segmentos do negócio será, sem dúvida, uma ferramer ta muito útil no gerenciamento de um hotel.

O serviço de reservas e de registro de hóspedes pode ser uma pre ciosa fonte de informações para o processo operacional e a satisfaçã dos clientes. Em geral, os dados necessários para o gerenciamento ef caz las atividades são simples de obter. O problema está em process os dados a tempo de permitir uma ação efetiva de controle e decisão.

É aí que a informática entra forte para ajudar. As tarefas comple xas não vão deixar de ser complexas só porque serão executalas por um computador, vão ser simplesmente executadas mais rapidamente.

Informatizar um hotel e fazer disso uma ferramenta de negócio começa necessariamente pelo planejamento do que se quer obter de informação e o que se deseja fazer com a mesma. Sem essa definição prévia qualquer atividade computadorizada será mera processadora de operações, sem qualquer finalidade gerencial. Se um hotel tiver um sistema de reserva processado por computador e este sistema não "falar" com a recepção, de nada adianta. Será apenas mais um serviço burocrático, que não adiciona qualquer benefício à gestão do negócio.

Um sistema informatizado não pode estar voltado somente para dentro da organização. Processar o controle de hóspedes, a contabilidade, o caixa, o estoque de alimentos e controlar o ativo fixo não satisfazem aos clientes se usados como puros registros das operações. Têm que dar à gerência informações efetivas para a gestão do negócio, produzir resultados e executar controles que ajudem a otimizar as operaçöes, satisfazer os clientes e proporcionar, como resultado natural, a melhor rentabilidade do negócio.

Um ambiente informatizado deve proporcionar aos clientes a possibilidade de obter todas as informações desejadas no âmbito da atividade $h$

tos, ativıdades disponíveis no hotel, horários de atividades e atrações, condiçoes de tempo, serviços de apoio para atividades profissionais (existentes ou não no hotel), entre outras coisas 
Recursos tecnológicos atualmente disponíveis, permitem ao hotel ter dados armazenados num sistema que o próprio hóspede aciona, colocados em locais de fácil acesso ou até mesmo através do aparelho de TV instalado no quarto. O sistema pode conduzir o hóspede através de um caminho onde ele poderia obter a informação desejada sem ne. cessidade de contactar qualquer empregado do hotel. O saldo da conta, a reserva de mesa no restaurante, o "check-out" (sob certas restriçōes), o pediđo de retirada do carro da garagem, o serviço despertador, a solicitação de reparo em instalaçōes do quarto, podem ser atividades colocadas à disposição đo hóspede ou usuário de um hotel. Exis. te tecnologia disponível para fazer qualquer destas açōes parecerem banais. É claro que tudo isto tem um custo, menor ou maior depen. dendo de onde se quer chegar.

Na minha profissäo, sou usuário frequente de senviços de hoteis, devido às viagens constantes que faço tanto no Brasil como ao cxtcrior, e tenho tido oportunidade de obscriar o uso da informática nestas organizaçoes. Freqüentemente me encontro no sitzaçào de nào ter resen'a num hotel simplesmente porque o setor de reserva nào comunicou • fato à recepçào ou o setor de crédito e cobrança ainda nùo deu sua accitação para faturar para a cmpresa. Os setores sáo estanques e náo se comunicam senäo através de processos burocráticos na base do papel, apesar de pessuírem computadores c redes de telcprocessamcinto.

Outros grandes cntraves à racionalizaçào e uso da informática é a cultura do papel, a falta de vontade de encarar nov'as formas de controle, de delegar c as rotinas ortodoxas de trabalho. Recentemente, num hotcl cinco estrclas, solicitci um extrato de minha conta c o cmpregado disse que näo poderia cmitir porque o sistema cstava bloqucado pclos auditores, fato que ocorria todas as madrugadas. Sc en tivesse quo fazcr o "check-out" àqucla hora, simplesmente teria de esperar que os senhores auditores libcrassem o sistema. Isto náo é informatizar.

Fatos desta natureza demonstram como a direção não levou em conta tais detalhes no "design" do sistema, simplesmente transportando para o computador o processo anteriormente estabelecido. Estes acontecimentos podem influir na escolha do hotel pelos hóspedes.

Informatizar é recepcionar o hóspede com uma ficha de registro semi-preenchida, baseada em dados obtidos por ocasião da reserva ou no registro anterior (se já existirem), ter designado o quarto adequado nos desejos do mesmo, ter a conta pronta e correta quando ele se apresenta para o "check-out" etc. Informatizar, em qualquer ramo de atividade, deve contemplar uma racionalização das atividades no seniido de tornar as tarefas de controle interno do negócio as majs eficientes e eficazes possíveis e responder com qualidade aos requerimentos dos clientes.

Outro cuidado importante em informatização é o dimensionamento do ámbiente de processamento de dados. Em hipótese alguma 28 deve-se adquirir equipamentos sem saber o que se pretende fazer com os mesmos. Apesar dos apelos quase irresistíveis da tecnologia, da necessidade de mostrar que, se está em dia com a modernidade, ou simplesmente querer demonstrar "status", deve-se resistir ao impulso e planejar o que se precisa com absoluto realismo e objetividade.

As informaçōes transmitem a imagem que os computadores fazem tudo que se deseja. É verdade, porém desde que se atenda a uma série de condiçōes as quais, na maioria das vezes, não são explicitadas pelos vendedores.

Os equipamentos devem atender ao objetivo definido, próximo ou futuro, serem capazes de armazenar e processar as informaçōes no tempo desejado, poderem ser expandidos, adaptados ou substituídos sem traumas. O empresário deve escolher profissionais competentes para instalar ou reformar seu ambiente de informática, mas não abrir mão de decidir o que se deseja fazer.

Nunca adapte seu negócio a um sistcma de informaçào c sim assegure-se que o sistema se adapte ao seu negócio. Se as duas coisas forcm convergentes, b́timo: temos a soluçäo que atende a todos:

Entender um pouco do que é oferecido no mercado pode ajudar bastante na análise das propostas e a separar o que serve do que não serve. Com a popularização dos computadores, recebe-se, hoje, uma "enxurrada" de informaçōes sobre capacidade, performance, modelos, características etc., especialmente em microinformática. É necessário, pois, conhecer os conceitos básicos de funcionamento dos computadores, seus limites, quais os recursos existentes no mercado, e as condições de negócio oferecidas. Tudo isto vai ajudar na hora da decisão.

Especial atenção deve ser dada aos chamados pacotes, sistemas prontos que são oferecidos no mercado. Muitos deles são dirigidos a atividades já consolidadas e com poucas possibilidades de mudanças, tais como: Contabilidade, Controle de estoques, Folha de pagamento. Outros, porém, são pacotes que pretendem cobrir ramos de atividade e muitas vezes não servem para a sua organização. A análise acuidada de $\mathrm{t}$

capital. Outro detalhe importante é que os pacotes devem poder "falar" uns com os outros, permitindo a transferência de informações entre os ambientes sem traumas ou processos demasiadamente complexos. Um fator de elevação de custos cm um ambiente de processamencompatibilizar a necessidade de agregar processos intermediários para compatibilizar sistemas e pacotes. 


\section{INFORMATIZAR É PRECISO, MAS CORRETAMENTE}

Finalizando, a informação deve ser precedida de um cuidadoso planejamento de todos os aspectos envolvidos, incluindo os processos, recursos materiais e humanos necessários, assegurando que estejam em perfeita sintonia com os resultados a atingir. Antes do computador deve vir o empresário com seu objerivo e o cliente com suas necessidades. A decisão pela aplicação do recurso tecnológico deve estar atrelada aos objetivos a alcançar em cada etapa e as atividades necessárias para tal. A informatização entra no como fazer e nunca no que fazer, e não pode ser o objetivo final, e sim a ferramenta que permitirá a execução da atividade da maneira mais produtiva e confiável. Informatizar é preciso sim, e sem dúvida irá colaborar para o sólido crescimento do negócio.

Informatize-se já, corretamente.

\section{BIBLIOGRAFIA}

1. CROSBY, Philip B. Qualidade é investimento. José Olímpio Editora, Rio de Janeiro, $1986,327 \mathrm{p}$.

2. DRUCKER, Peter F. O gerente eficáz. Zahar Editores, Rio de Janeiro, 1977, 184p.

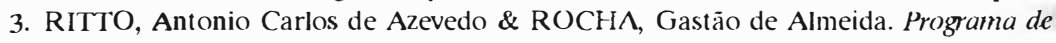
Informática. LTC Rio de Janeiro, 17 módulos.

4. STRASSMANN, Paul A. Os frutos da informática. José Olímpio, Rio de Janeiro, 1986, 358p. 